\title{
Tooth Loss Prevalence and Risk Indicators in an Isolated Population of Kadapa- South India
}

\author{
P. Sesha Reddy ${ }^{1}$, A. Swaroop Kumar Reddy ${ }^{2}$, Ashish. R. Jain ${ }^{3, *}$, R. Pradeep ${ }^{3}$ \\ ${ }^{1}$ Department of Prosthodontics, Government Dental College and Hospital, Rajiv Gandhi Institute of Medical science, kadapa, India \\ ${ }^{2}$ Department of Endodontics, Narayana Dental Colleg, PSR Nellore, India \\ ${ }^{3}$ Department of Prosthodontics, Tagore Dental College and Hospitals, Chennai, India \\ *Corresponding author: dr.ashishjain_r@yahoo.com
}

Received August 20, 2014; Revised November 07, 2014; Accepted November 11, 2014

\begin{abstract}
Background: Loss of teeth is mainly attributed to dental caries and periodontal diseases. Factors relating to tooth extractions are not, however, always dental in origin. Edentulousness and small number of remaining teeth are associated with low educational level, low family income and rural domicile. Aim: To evaluate the risk factors for tooth loss and to establish base line data about missing teeth, among patients attending OPD of Govt. Dental College and, Hospital, RIMS, Kadapa. Materials and methods: A sample of 150 patients, age group of 18 years and above with non- disease as factors for tooth loss, are considered. The subjects were interviewed with a structured questionnaire regarding age, sex, marital status, demographics, socioeconomic status, smoking habits, dental visiting patterns, and oral hygiene practices, and then clinically examined by a single examiner for number of missing teeth. Univariant analysis is carried out and those variables which show statistical significance Association between loss of teeth and selected variables are studied using Chi square test. Results: Of the 150 patients, 55 (36.7\%) were males and 95 (63.4\%) were females and mean age was 35.5 years with an average of $10.7 \%$ of teeth missing per person. Subjects with no schooling had more than 2 missing teeth, current smokeless tobacco users and non regular dental visiting pattern had more than 2 missing teeth. Smoking had no association with the missing teeth. Women than men, Education and the family income were also significantly associated with the number of missing teeth. Conclusion: Though most of the individual risk factors do lead to periodontal disease and loss of teeth, the present study has a drawback where smoking and tooth loss did not show any association. On the basis of the evidence presented it would seem that the loss of one's natural teeth is a complex social and environmental phenomenon and is not merely a result of dental disease. This study demonstrates that modifications in the nondisease factors (education, income, smoking) could reduce the number of missing teeth and improve oral health status and function.
\end{abstract}

Keywords: risk factors, tooth loss, Socio-demographic and economic status, gender, age, oral hygiene practices

Cite This Article: P. Sesha Reddy, A. Swaroop Kumar Reddy, Ashish. R. Jain, and R. Pradeep, "Tooth Loss Prevalence and Risk Indicators in an Isolated Population of Kadapa- South India.” Journal Name, vol. 2, no. 6 (2014): 221-225. doi: 10.12691/ajphr-2-6-1.

\section{Introduction}

Dental status is related to a number of social and socioeconomic factors. A higher proportion of edentulous individuals and a lower number of remaining teeth in dentulous subjects have been found in low socio economic classes and in groups with poor educational back ground [1]. Loss of teeth is mainly attributed to dental caries and periodontal diseases. Factors relating to tooth extractions are not, however, always dental in origin. Edentulousness and small number of remaining teeth are associated with low educational level, low family income and rural domicile. Dental caries and periodontitis are caused by microorganisms, but age, gender, socioeconomic status, oral hygiene habits, tobacco usage and regular dental visiting patterns may modify the progression of these diseases. Others reported factors associated with missing teeth include level of education, income, oral hygiene practices, marital status, gender and smoking [2].

In research dealing with major chronic diseases, i.e cardiovascular disorders and cancer, more emphasis has been directed towards the combined influence of lifestyle, psychological factors and social conditions, instead of standard risk factors. In recent years, this idea has spread to dentistry as well [3].

Aim: The Purpose Of This Study Is To Evaluate The Risk Factors For Tooth Loss And To Establish Baseline Data About Missing Teeth Among Patients.

\section{Methodology}

Sample selection: study is a cross sectional observational study, where all adult patients aged 18 years and above attending OPD of Govt. Dental College and Hospital, Kadapa were screened for tooth loss. A sample 
size of 150 patients was determined on assuming that on an average 6 to 7 patients were observed with tooth loss, which sums up to 150 for one month study period. An attempt was made to select the patients with non-biologic factors (socio-demographic and economic characteristics, marital status, smoking habits, oral hygiene practices and methods, etc...) as indicators for tooth loss. Three age groups were classified, i.e. 25-34 yrs, 35-44 yrs and >44 yrs (since the subjects in the study sample found were above 25 years). Prior informed consent was taken from the study population.

\subsection{Inclusion Criteria}

- Age group of 18 years and above with tooth loss.

\subsection{Exclusion Criteria}

- Biologic factors (caries and periodontal diseases)

- Systemic diseases

- $3^{\text {rd }}$ molars (missing)

\subsection{Interview and Clinical Examination}

Baseline data were collected using structured questionnaire with personal interviews and that followed by clinical examination. Baseline interview was extensive and included questions regarding, name, age, gender, socio-demographic and socio-economic characteristics, marital status, smoking habits, dental visiting patterns, use of dental services and methods, self perceived oral health status and dental care. Clinical examination was carried out in the OPD of Oral medicine department; to identify the missing teeth using DMFT index. The patient was placed on the dental chair and with help of artificial illumination, sterilized mouth mirrors, probes, cotton rolls, mouth masks and examination gloves, the findings were self entered into a pretested questionnaire. Single examiner performed all examinations and interviews.

\subsection{Statistical Analysis}

- Data processing and analysis were carried using statistical packages, namely SPSS 11.0.P-value less than $0.005(\mathrm{P}<0.005)$ is considered as statistically significant, at corresponding Degrees of freedom (df).

- Loss of teeth was categorized into, $<2$ and $>2$.

- Univariant analysis is carried out.

- Association between loss of teeth and selected variables are studied using Chi square test.

\section{Results}

Table 1. Distribution of study subjects by age group

\begin{tabular}{|c|c|c|c|}
\hline AGE IN YEARS & Males & Females & overall \\
\hline $25-34$ Yrs & $13(8.6 \%)$ & $29(19.3 \%)$ & $42(28 \%)$ \\
\hline $35-44$ Yrs & $31(20.6 \%)$ & $54(36 \%)$ & $85(54.7 \%)$ \\
\hline >44 Yrs & $11(7.3 \%)$ & $12(8 \%)$ & $23(15.3 \%)$ \\
\hline Total & $55(36.7 \%)$ & $95(63.4 \%)$ & $150(100 \%)$ \\
\hline
\end{tabular}

Table 1 demonstrates distribution of subjects by age and sex. The study population consisted of 150 subjects, of whom males were $55(36.7 \%)$ and females were 95 (63.4\%). Over all subjects in the age group of 25-34 years males were 13 (8.6\%), females were 29 (19.3\%), among 35-44 years age group, males were 31 (20.6\%) and females were 54(36\%) and among > 44 years age group, males were $11(7.3 \%)$ and females were $12(8 \%)$.

Males residing in the urban locality were 9 (16.3\%), females were $21(22.1 \%)$ and those residing in the rural locality, males were $46(83.6 \%)$ and females were 74 (77.9\%). Single males were 2 (3.6\%), females were 1 (1\%), and married males were 53 (98.1\%) and females were 94 (98.9\%) (Table 2).

Subjects earning 2000-5000 rs monthly were, males 1 , females 28 (29.5\%), 5001-10000 rs monthly males were 17 (30.9\%), females were $49(51.8 \%)$ and more than 10,000 rs monthly males were $37(67.2 \%)$ and females were 18 (18.9\%). (Table 2).

Table 2. Estimates of variables affecting tooth loss

\begin{tabular}{|c|c|c|c|c|c|}
\hline & Male & & Female & & Total \\
\hline & $\mathrm{N}$ & $\%$ & $\mathrm{~N}$ & $\%$ & $\mathrm{~N}$ \\
\hline $\begin{array}{c}\text { Place of residence } \\
\text { Urban }\end{array}$ & 9 & 16.3 & 21 & 22.1 & 30 \\
Rural & 46 & 83.6 & 74 & 77.9 & 120 \\
\hline Marital status & & & & & \\
Married & 53 & 98.1 & 94 & 98.9 & 147 \\
Single & 2 & 3.6 & 1 & 1 & 3 \\
\hline Family income & & & & & \\
2000-5000/month & 1 & 1 & 28 & 29.1 & 29 \\
5000-10000/month & 17 & 30.9 & 49 & 51.8 & 66 \\
$>10000 /$ month & 37 & 67.2 & 18 & 18.9 & 55 \\
\hline Total & 55 & \multicolumn{5}{|c|}{95} & & 150 \\
\hline
\end{tabular}

Table 3 demonstrates distribution of subjects by level of education: subjects who did not attend school were, males 3 (5.4\%), females 42 (44.2\%), subjects with primary schooling were, males 20 (36.3\%), females 20 (21\%), subjects with high school education were, males 6 (10.9\%), females $10(10.5 \%)$ and subjects with graduation males were 26 (47.2\%) and females were 23 (24.2\%).

Table 3. Distribution of study subjects by education

\begin{tabular}{|c|c|c|c|c|c|}
\hline Education & Male & & Female & & Total \\
\hline & $\mathrm{N}$ & $\%$ & $\mathrm{~N}$ & $\%$ & \\
\hline No Schooling & 3 & 5.45 & 42 & 44.21 & 45 \\
\hline Primary & 20 & 36.36 & 20 & 21.05 & 40 \\
\hline High School & 6 & 10.91 & 10 & 10.53 & 16 \\
\hline Graduate & 26 & 47.27 & 23 & 24.21 & 49 \\
\hline Total & 55 & 100 & 95 & 100 & 150 \\
\hline
\end{tabular}

Table 4. Distribution of subjects' responses regarding Dental visit

\begin{tabular}{|c|c|c|c|c|c|}
\hline LAST DENTAL VISIT & Male & & Female & & Total \\
\hline & $\mathrm{N}$ & $\%$ & $\mathrm{~N}$ & $\%$ & $\mathrm{~N}$ \\
\hline First time & 15 & 27.2 & 49 & 51.6 & 64 \\
\hline Within last year & 13 & 23.6 & 23 & 24.2 & 36 \\
\hline More than a year & 27 & 49.1 & 23 & 24.2 & 50 \\
\hline Total & 55 & & 95 & & 150 \\
\hline
\end{tabular}

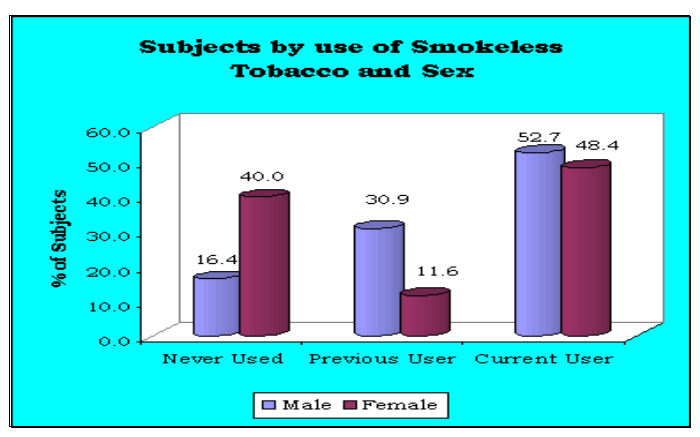

Graph 1. Distribution of Subjects By Usage Of Smokeless Tobacco

Among subjects who never smoked, males were 2 (3.6\%). Females were 84(88.4\%), previous smokers males were $10(18.2 \%)$, females were $6(6.3 \%)$ and current 
smokers males were $43(78.2 \%)$ and females were 5 (5.3\%).

Graph 1 depicts distribution of subjects by usage of smokeless tobacco; subjects who never used tobacco were males 9 (16.4\%), females were 38 (40\%), previous users males were 17 (30.9\%), females were 11 (11.5\%) and current users were males 29 (52.7\%) and females were 46 (48.4\%).

Graph 2 depicts distribution of subjects by dentist visiting pattern; subjects who visited dentist regularly were, males 7 (12.7\%), females 29 (30.5\%) and not regular visitors were males 48 (87.2\%) and females 66 (69.4\%).

Subjects visiting dentist for the first time were, males 15 (27.2\%), females were 49 (51.6\%), visit within the last year were, males 13 (23.6\%), females 23 (24.2\%) and

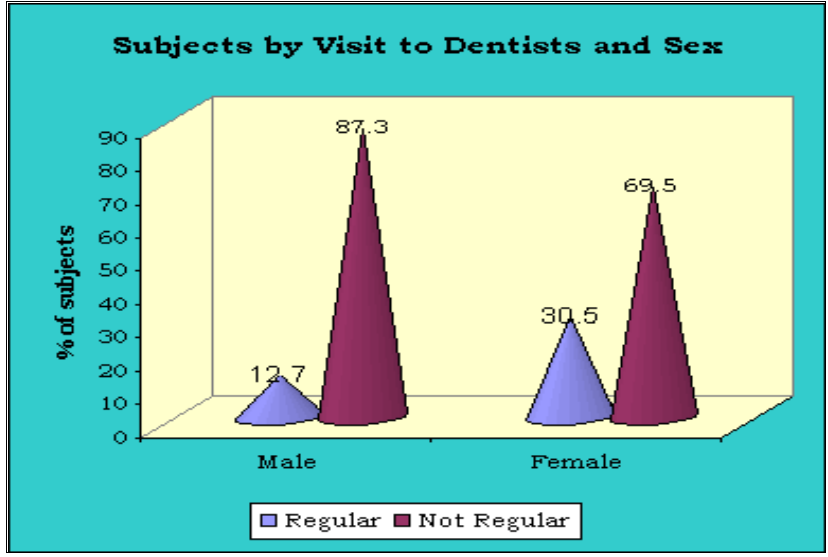

Graph 2. Distribution of Subjects by Dentist Visiting Pattern subjects visiting dentist more than a year ago, males were 27 (49.1\%) and females were 23 (24.2\%). (Table 4).

Table 5. Distribution of study subjects by Oral hygiene practices

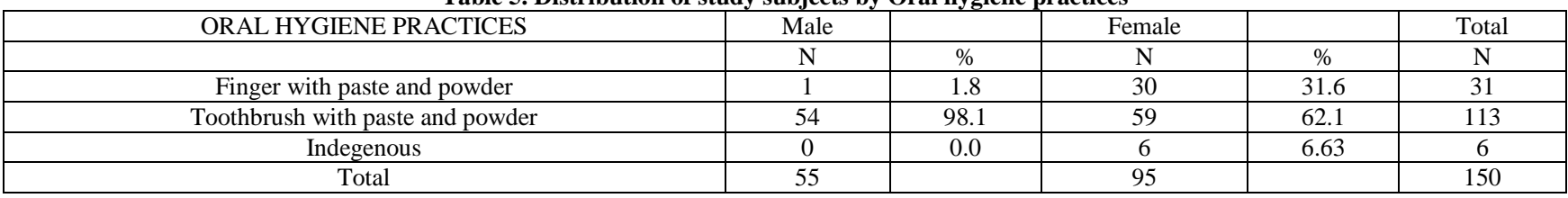

Oral hygiene practices; subjects oral hygiene practice with fingers, males were 1 (1.8\%), females were 30 (31.6\%); using tooth brush, males were 54 (98.1\%),

females were 59 (62.1\%) and indigenous practices females were 6 (6.3\%). (Table 5).

Table 6. Distribution Of Study Subjects By Self Rated Oral Health

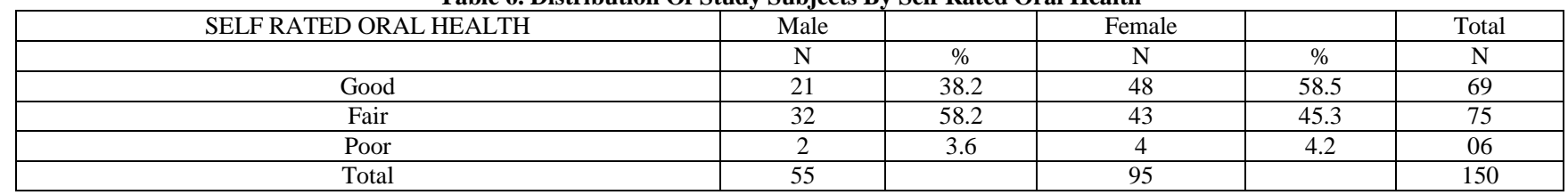

Table 7. Distribution Of Study Subjects By Self Perceived Need For Dental Care

\begin{tabular}{|c|c|c|c|c|c|}
\hline SELF PERCEIVED NEED FOR DENTAL CARE & Male & & Female & & Total \\
\hline & $\mathrm{N}$ & $\%$ & $\mathrm{~N}$ & $\%$ & $\mathrm{~N}$ \\
\hline Yes & 55 & 100 & 91 & 95.8 & 146 \\
\hline No & 0 & 0.0 & 04 & 4.2 & 4 \\
\hline Total & 55 & & 95 & & 150 \\
\hline
\end{tabular}

Distribution of subjects by self rated oral health: subjects those who rated their own oral health status as good were, males 21 (38.2\%), females 48 (50.5\%), as fair were males 32 (58.2\%), females were 43 (45.3\%) and those who rated poor were, males 2 (3.6\%) and females were 4 (4.2\%). (Table 6).

Distribution of subjects by self perception need for dental care: subjects those who felt the need for dental care were, males 55 (100\%) and females 91 (95.8\%) and those who didn't feel the need for dental care were females 4 (4.2\%). (Table 7).

Table 8. Distribution of study subjects by number of teeth missing

\begin{tabular}{|c|c|c|c|c|c|}
\hline No. of Teeth missing & Male & & Female & & Total \\
\hline & $\mathrm{N}$ & $\%$ & $\mathrm{~N}$ & $\%$ & $\mathrm{~N}$ \\
\hline 1 & 12 & 21.82 & 12 & 12.63 & 24 \\
\hline 2 & 8 & 14.55 & 32 & 33.68 & 40 \\
\hline 3 & 31 & 56.36 & 41 & 43.16 & 72 \\
\hline 4 & 3 & 5.45 & 8 & 8.42 & 11 \\
\hline 5 & 1 & 1.82 & 2 & 2.11 & 3 \\
\hline Total & 55 & & 95 & & 150 \\
\hline
\end{tabular}

Table 8 demonstrates distribution of subjects with number of missing teeth: subjects who had one missing tooth were males 12 (21.8\%), females were 12 (12.6\%); subjects with 2 missing teeth, males were 8 (14.5\%), females were 32 (33.9\%); subjects with 3 missing teeth were, males 31 (56.4\%), females were 41 (43.2\%); subjects with 4 missing teeth, males were 3 (5.4\%), females were 8 (8.4\%); and subjects with 5 and more missing teeth were, males $1(1.8 \%)$ and females were 2 (2.1\%).

\section{Discussion}

Dental status is multidimensional, and several studies have investigated the risk indicators of missing teeth in different parts of the world. Indicators of tooth loss reflect oral impairment and indicators of tooth retention reflect oral health and well-being and dental status is related to a number of social and socioeconomic factors [4]. A higher proportion of edentulous individuals and a lower number of remaining teeth in dentulous subjects have been found in low socio economic classes and in groups with poor educational back ground [5]. With age being the most commonly reported factor associated with missing teeth, 
and older people exhibit a higher number of missing teeth and a lower number of natural teeth remaining [6].

Caries variables and periodontal disease variables seem to be important predictors of occurrence of tooth loss, but at the tooth level, caries would seem to be predominant cause of tooth loss in all age group. [7] Other reported factors associated with missing teeth include education, income, oral hygiene practices, marital status, gender and smoking. [8] Subject's education and income are among the factors that influence a decision to extract teeth. [9] The present observational study includes a sample size of 150 adult population, 18 years and above, with males 55 (36.7\%) and females 95 (63.4\%) with tooth loss.

Distribution of subjects in the age group of 18-34 years were 42 subjects, in the age group of 35-44 years were 85 subjects and $>44$ years were 23 subjects. The incidence of $>2$ tooth loss was seen in the age of 35 years. In the present study females had $>2$ tooth loss, this can be explained by the fact that $74(77.8 \%)$ of them were rural residents, 42 (42.2\%) of them had not attended the school, $46(48.4 \%)$ were current users of smokeless form of tobacco, 66 (69.4\%) of them were not regular visitors to the dentist, 49 (51.5\%) were first time visitors to the dentist, $23(24.2 \%)$ had visited the dentist in the last year and 30 (31.5\%) used fingers to brush their teeth.

The results of the present study was consistent to that of the study of Hamasha A.H et al in their paper "Risk indicators associated with tooth loss in Jordanian adults" in the year 2000, showed that females had more missing teeth compared to males and the mean number of missing teeth increased significantly with age, $46 \%$ were from rural domicile, $18 \%$ were illiterates with no previous schooling, 46\% brushed their teeth irregularly, 33.8\% smoked and 29\% had visited dentist in the last year [10]. Amarasena $\mathrm{N}$ et al in 2003 found that the mean number of teeth lost in the sample was $5.17+/-5.43$. Tooth loss increased significantly with age [11].

The positive effect of cleaning the teeth with tooth brush twice daily resulting in greater tooth retention is consistent with the results of other studies. Less tooth loss among tooth brush users may be due to superior plaque control among them, as the bristles of the tooth brush can reach the interproximal areas as well as pits and fissures of the teeth more efficiently than finger or other indigenous materials, thus resulting in better oral hygiene.

Susin C et al in 2006 observed that subjects with gender, marital status, self-rating of oral health status, regular dental visiting pattern had less number of missing teeth [12].

Lopez $\mathrm{R}$ et al in their study showed that tooth loss was related to low socioeconomic status and the present study also revealed the same [13].

Wennström A et al in 2013 observed that, there is a significant relationship between fewer teeth and a lower social group, and among the 50-year-old women, this was irrespective of examination year. However, multivariate analyses showed that the risk to be edentulous or not, or to have fewer remaining teeth was significantly higher for women of lower social group, or living alone [14].

Hanioka T et al in 2007 found association of tooth loss was non-significant in former smokers but significant in current smokers: adjusted odds ratios (95\% confidence intervals) relative to nonsmokers in males and females were $1.29(0.92-1.80)$ and $0.86(0.46,1.60)$ for former smokers and 2.22 (1.61-3.06) and 2.14 (1.45-3.15) for current smokers, respectively. A dose-response relationship between lifetime exposure and tooth loss was seen ( $\mathrm{P}$ for trend $<0.0001$ ). [15] But, interestingly there was no association found between smoking and tooth loss in the present study.

Majority did not feel they had any problem in their oral cavity. The self perceived oral health status and need for treatment are important factors that influence utilization of dental services. The low level of utilization of dental services suggest that people tend to overestimate their dental health and underestimate their need for care and those who underestimate their own dental care needs utilize the services.

From an epidemiological perspective, further research is needed with larger sample size, which includes dental caries and periodontal disease as risk factors for tooth loss.

\section{Conclusion}

The above cross sectional observational study reveals six significant risk factors for tooth loss; namely education, usage of smokeless tobacco, dental visiting pattern, last dental visit, oral hygiene practices and self rated oral care. Though most of the individual risk factors do lead to periodontal disease and loss of teeth, the present study has a drawback where smoking and tooth loss did not show any association. On the basis of the evidence presented it would seem that the loss of one's natural teeth is a complex social and environmental phenomenon and is not merely a result of dental disease. This study demonstrates that modifications in the non-disease factors (education, income, smoking, attitude and beliefs) could reduce the number of missing teeth and improve oral health status and function.

\section{Reference}

[1] Ahlqwist m.Bengstsson C, Grondahl H-G, Lapidus L: Social factors and tooth loss in a 12 year follow up study of women in Gothenburg, Sweden, CDOE 1991; 19: 141-6.

[2] Casanova-Rosado JF Medina-Solis CE Lifestyle and psychosocial factors associated with tooth loss in Mexican adolescents and young adults. J Contemp Dent Pract. 2005 Aug 15; 6 (3): 70-7.

[3] Sakki TK. Knuuttilla MLE, Anttilla SS; Lifestyle, gender and occupational status as determinants of dental health behavior. JClin Periodontol 1998; 25: 566- 570

[4] Barbato PR, Muller Nagano HC, Zanchet FN, Boing AF, Peres MA, Tooth loss and associated socioeconomic, demographic, and dental-care factors in Brazilian adults: an analysis of the Brazilian Oral Health Survey, 2002-2003] Cad Saude Publica, 2007 Aug; 23 (8): 1803-14.

[5] Xie Q, Ainamo A: Association of edentulousness with systemic factors in elderly people living at home, CDOE 1999; 27: 202-9.

[6] D.Locker, j. Ford, and J.L Leake; Incidence of and risk factors for tooth loss in a population of older Canadians, JDent Res 75 (2): 783-789, Feb 1996.

[7] Eklund SA, Burt BA. Risk factors for total tooth loss in the United States; longitudinal analysis of national data J Public Health Dent. 1994 Winter; 54 (1): 5-14.

[8] Ahlqwist m.Bengstsson C, Hollender L, Osterberg T: Smoking habits and tooth loss in Swedish women. CDOE 1989; 17: 144-7.

[9] Susin C, Oppermann RV, Haugejorden O, Albandar JM, Tooth loss and associated risk indicators in an adult urban population from south Brazil. Acta Odontol Scand., 2005 Apr; 63 (2): 85-93. 
[10] Hamasha AH., Sasa I, Al Quadah M: Risk indicators associated with tooth loss in Jordanian adults, CDOE 2000; 28: 67-72.

[11] Amarasena N, Ekanayaka AN, Herath L, Miyazaki H,. Sociodemographic risk indicators for tooth mortality in rural Sri Lankans. Asia Pac J Public Health, 2003; 15 (2): 105-10.

[12] Susin C, Haas AN, Opermann RV, Albandar JMTooth loss in a young population from south Brazil. J Public Health Dent. 2006 spring; 66 (2): 110-5.
[13] López R, Baelum V. Gender differences in tooth loss among Chilean adolescents: socio-economic and behavioral correlates. Acta Odontol Scand 2006 Jun; 64 (3): 169-76.

[14] Wennström A, Ahlqwist M, Stenman U, Björkelund C, Hakeberg. $\mathrm{M}$. Trend in tooth loss in relation to socio-economic status among Swedish women, aged 38 and 50 years: repeated cross-sectional surveys 1968-2004. BMC Oral Health. 2013 Nov 6; 13 (1): 63.

[15] Hanioka T, Ojima M, Tanaka K, Aoyama HRelationship between smoking status and tooth loss: findings from national databases in Japan. J Epidemiol., 2007 Jul; 17 (4): 125-32. 